\title{
Strengthening CoCrNi medium-entropy alloy by tuning lattice defects
}

Hua Huang ${ }^{1, \#}$, Jianying Wang ${ }^{1, \#}$, Hailin Yang ${ }^{1, *}$, Shouxun $\mathrm{Ji}^{2}$, Jianming Ruan ${ }^{1}$, Zhilin Liu ${ }^{3, *}$ 1. State Key Laboratory of Powder Metallurgy, Central South University, Changsha 410083, China 2. BCAST, Brunel University London, Uxbridge, Middlesex, UB8 3PH, United Kingdom

3. Light Alloy Research Institute, College of Mechanical and Electrical Engineering, Central South University, Changsha, 410083, P.R. China

\# These authors contributed equally to this work.

* Corresponding authors: y-hailin@csu.edu.cn; zhilin.liu@csu.edu.cn

\begin{abstract}
:
The CrCoNi medium-entropy alloy is not fully utilized at room temperature circumstance due to its low strength, despite excellent cryogenic mechanical properties. Here we report that, a superior room temperature strength $(1.6 \mathrm{GPa}$ and $407.6 \mathrm{Hv})$ has been obtained in the single phase CoCrNi medium-entropy alloy, by carefully tuning the formation of multiple lattice defects. Electron microscopy characterizations show that such high-strength CoCrNi alloy contains favourable heterostructures of coarsening grains $(\sim 30 \mu \mathrm{m})$ and ultrafine grains $(\sim 1 \mu \mathrm{m})$, together with the high density of dislocation cells, small stacking faults, ultrafine nanotwins $(\sim 9 \mathrm{~nm}$ in thickness) and Lomer-Cottell locks.
\end{abstract}

Keywords: Medium-entropy alloys; Microstructure; High strength; Lattice defects; Strengthening mechanisms

The engineering alloys with ultra-high strength are highly desired for load-bearing applications. As a new class of metallic materials, the CoCrNi medium-entropy alloy with equimolar multicomponent has attracted wide interests due to its promising mechanical properties [1-8], in particular at cryogenic environment [9]. Usually, the tensile strength of single face-centred cubic (f.c.c) phase CoCrNi is very low in the absence of additional strengthening [10]. However, the medium-entropy alloys with only single phase, in particular for f.c.c lattice structure, may not deliver desirable strength for engineering application [2, 11]. Thus, various strategies of architecting extrinsic strengthening mechanisms have been exerted, including deformation twinning [9, 11, 12s], annealing twinning [13], alloying solutes [8], precipitation [10, 14], grain refinement [2, 7, 15], grain boundary relaxation [6], heterogeneous structures [1,3, 5], short-range order [16], and other high density defects [4].

Such strengthening mechanisms essentially depend on creating single or multiple lattice defects, but with different fractions. The representative defects, reported in the entropy-based CoCrNi alloys, include point defects (interstitial $\mathrm{C} / \mathrm{Al} / \mathrm{Mo}$ atoms [8, 17]), linear defects (dislocations [4], and Lomer-Cotrell locks [2]), interface defects (twins [1, 2, 4, 5, 12], stacking faults [10], and grain boundaries [1, 2, 5, 6]), and volume defects (precipitates [3, 10], and f.c.c - 
h.c.p phase transition $[4,18,19])$. Using ab initio modelling, the CoCrNi medium-entropy alloy has been shown to exhibit low stacking-fault energy [20]. It possesses, therefore, high propensity to form some lattice defects such as twins and stacking faults. Actually, the mechanical strength of metallic materials would vary with different combination of lattice defects. For instance, the suitable combination of dislocations, twins, stacking faults and f.c.c-h.c.p phase transformation in the CoCrNi alloy imparted a good strength-ductility synergy [2, 4, 11, 20, 21].

This work explores a feasible processing route to obtain high-strength f.c.c CoCrNi alloy by merely controlling the lattice defects. Specifically, the CoCrNi alloy bulk sample was synthesized using spark plasma sintering (SPS), followed by different processing (i.e. rolling and annealing). Different degrees of combination of the lattice defects, including grain boundaries, dislocations, stacking faults, twins and Lomer-Cottell locks, were attained. Then, the effects of different processing on the lattice defects and associated mechanical properties of CoCrNi alloys were investigated. Further, the dominant mechanisms responsible for tensile deformations were discussed.

The CoCrNi pre-alloyed powder was prepared by the high-pressure $\mathrm{N}_{2}$ gas atomization at a temperature of $1670{ }^{\circ} \mathrm{C} . \mathrm{N}_{2}$ nozzle was operated at a pressure of $1.8 \mathrm{MPa}$. The powder was stored in a bag fulfilled with inert gas for oxidation elimination. Details of the pre-alloyed CoCrNi powders are listed in Supplementary Fig. S1(a). The purity of raw powders was determined at $\sim 99.9$ wt. $\%$. The majority of raw powders displayed a spherical morphology. During experiments, the CoCrNi powders were compacted and consolidated by SPS in the graphite die with an inner diameter of 40 $\mathrm{mm}$. SPS treatment was carried out at $1080^{\circ} \mathrm{C}$ for 15 min under a uniaxial pressure of $40 \mathrm{MPa}$. Heating rate was set to be $100{ }^{\circ} \mathrm{C} / \mathrm{min}$. After SPS treatment, the CoCrNi samples were air cooled to $25{ }^{\circ} \mathrm{C}$. The carbon layer over the SPSed CoCrNi alloy was removed by mechanical polishing. Then, rolling at $25{ }^{\circ} \mathrm{C}$ was applied to the CoCrNi samples to reduce its thickness by $50 \%$. The annealing of $\mathrm{CoCrNi}$ alloy samples was individually conducted in an electric resistance furnace at $600{ }^{\circ} \mathrm{C}$ and $700{ }^{\circ} \mathrm{C}$. These annealed samples were subsequently cooled inside the furnace to reach $25{ }^{\circ} \mathrm{C}$.

Afterwards, an electrical discharge machining (EDM) was used to make the tensile samples, which have a gauge length of $12.5 \mathrm{~mm}$ and a cross-section of $3.2 \mathrm{~mm}$ (width) $\times 1.4 \mathrm{~mm}$ (thickness). Meanwhile, cubic samples with geometrical dimensions of $1 \mathrm{~cm} \times 1 \mathrm{~cm} \times 3 \mathrm{~cm}$ was prepared for hardness measurement. Phase identification was implemented utilizing X-ray diffraction technique (XRD, Rigaku), performed at $40 \mathrm{kV}$ with $\mathrm{Cu} K_{\alpha}$ radiation $\left(\lambda_{\mathrm{ka}}=1.54 \AA\right)$. Rotation angles spanned from $30^{\circ}$ to $100^{\circ}$ at a step size of $0.02^{\circ}$. XRD spectra of the pre-alloyed powders and the CoCrNi alloys under different treatments are shown in Fig. S1(b). Microstructural characterization was executed by scanning electron microscope (SEM, Quanta 250 FEG), electron backscatter diffraction (EBSD) at an accelerating voltage of $25 \mathrm{kV}$, and transmission electron microscope (TEM) operated at $200 \mathrm{kV}$ (Tecnai G2 F20). Uniaxial tensile deformation was performed on a material testing system (Instron, Model 3369) with an engineering strain rate of $1 \times 10^{-3} \mathrm{~s}^{-1}$. The microhardness was measured on a Vicker hardness testing machine (600 HVS-1000AVT) with a loading force of $100 \mathrm{~g}$ and a dwelling time of $15 \mathrm{~s}$. In order to eliminate the measurement errors, each data was an average value collected from 6 - 10 tests.

The tensile properties of CoCrNi alloys under different treatments are shown in Fig. 1(a). The as-SPSed alloys show a yield strength of $0.45 \mathrm{GPa}$, ultimate tensile strength (UTS) of $0.85 \mathrm{GPa}$ and fracture strain of $46 \%$. After rolling at $25{ }^{\circ} \mathrm{C}$, the yield strength increased to $0.675 \mathrm{GPa}$, UTS 
increased to $1.025 \mathrm{GPa}$ and the fracture strain presented at $27.5 \%$. Moreover, the yield strength, UTS, and fracture strain of the CoCrNi alloys annealed at $600{ }^{\circ} \mathrm{C}$ for $1 \mathrm{~h}$ are $1.426 \mathrm{GPa}, 1.615 \mathrm{GPa}$, and $7 \%$, respectively. Clearly, annealing introduced significant increase in strength, compared with pure rolling. At an elevated annealing temperature of $700{ }^{\circ} \mathrm{C}$, the yield strength (or the UTS) increased to $1.575 \mathrm{GPa}$ (or $1.625 \mathrm{GPa}$ ), while the fracture strain decreased to $5 \%$. Fig. 1(b) demonstrates a comparison of tensile properties (i.e. strength and elongation) between the experimental CoCrNi alloys and other engineering materials [22-25]. It can be seen that the alloy in the present work exhibits a better combination of strength and ductility. Hardness of CoCrNi MEAs under different treatments is shown in Fig. S2. The average hardness of as-SPSed CoCrNi alloys varied between $202.5 \mathrm{Hv}$ and $233.2 \mathrm{Hv}$. After $50 \%$ rolling reduction in thickness at $25{ }^{\circ} \mathrm{C}$, the hardness of CoCrNi alloys varied between $313.6 \mathrm{Hv}$ and $382.4 \mathrm{Hv}$. The hardness increased gradually as increasing the annealing temperatures, reaching the peak value $(415.8 \mathrm{Hv})$ at $500{ }^{\circ} \mathrm{C}$ from $375 \mathrm{Hv}$ at $400{ }^{\circ} \mathrm{C}$. A plateau $(\sim 415.8 \mathrm{Hv})$ appeared between $500{ }^{\circ} \mathrm{C}$ and $600{ }^{\circ} \mathrm{C}$, followed by gradually decreasing to $245 \mathrm{Hv}$ at $800^{\circ} \mathrm{C}$. All determined results are summarized in Table 1 .
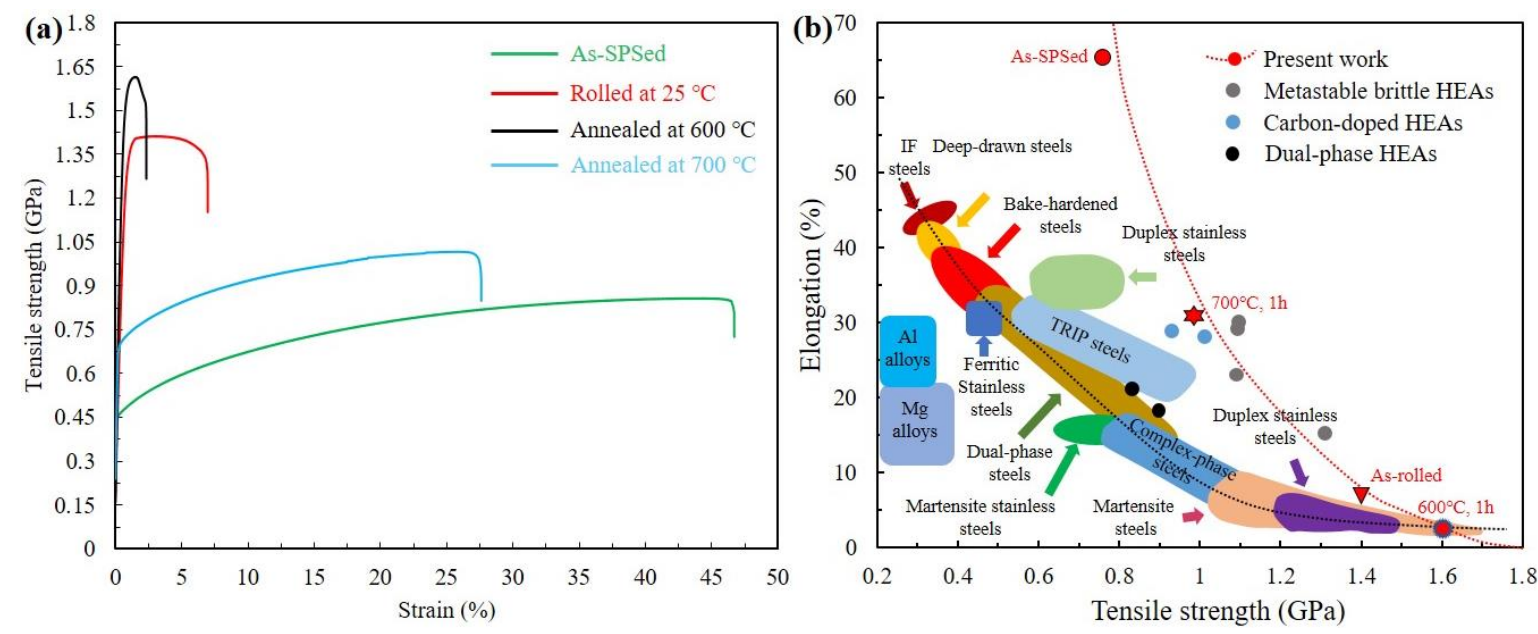

Fig. 1. (a) Tensile stress-strain curves of the CoCrNi medium-entropy alloys under different treatments; (b) Comparison of the tensile properties between the CoCrNi alloy and other engineering materials [22-25].

Table 1 The yield strength (YS), ultimate tensile strength (UTS), fracture strain (FS), and hardness determined for the CoCrNi alloys by different treatments.

\begin{tabular}{lllll}
\hline Treatment & YS (GPa) & UTS (GPa) & FS (\%) & Hardness (Hv) \\
\hline As-SPSed & 0.48 & 0.86 & 47.5 & 215.2 \\
Rolling & 1.24 & 1.41 & 7.0 & 350.7 \\
${ }^{a}$ Rolling + annealing & 1.43 & 1.61 & 2.3 & 407.6 \\
${ }^{b}$ Rolling + annealing & 0.70 & 1.02 & 27.6 & 278.4 \\
\hline
\end{tabular}

All rolling for $50 \%$ reduction at $25{ }^{\circ} \mathrm{C}$; ${ }^{a}$ annealing at $600{ }^{\circ} \mathrm{C}$ for $1 \mathrm{~h} ;{ }^{b}$ annealing at $700{ }^{\circ} \mathrm{C}$ for $1 \mathrm{~h}$. 
XRD spectra identified only single f.c.c phase in all samples, as shown in Fig. S1(b). Fig. 2(a)-(d) shows the EBSD orientation mapping of the CoCrNi alloys processed by SPS, cold-rolling, and annealing at $600{ }^{\circ} \mathrm{C}$ and $700{ }^{\circ} \mathrm{C}$, respectively. The heterostructures (i.e. large grains coupled with small grains) were observed in all samples. The as-SPSed CoCrNi alloys had most coarsening grains, with minor microscale twins in Fig. 2(a). Grain structures in Fig. 2(b) and (c) were highly elongated with severe lattice distortion. Comparing Fig. 2(b) and (c), annealing at $600{ }^{\circ} \mathrm{C}$ could not substantially relieve texture of the as-rolled CoCrNi alloys. However, significant grain refinement occurred after annealing at $700{ }^{\circ} \mathrm{C}$ due to recrystallization, as shown in Fig. 2(d). Based on the clean grain boundaries, the average grain size was determined to be $\sim 2.0 \mu \mathrm{m}$. Annealing at $700{ }^{\circ} \mathrm{C}$ generated the high-angle grain boundaries with misorientation $>15^{\circ}$ (see Fig. S3). The misorientation angles appeared strongly at $60^{\circ}$. Fracture micrographs of the CrCoNi alloys with different treatments are shown in Fig. 2(e)-(h). The dimple-like structures appeared on the cross-sections of fractured tensile samples, i.e. most coarsening in Fig. 2(e), moderate coarsening in Fig. 2(f) and (g), and smallest in Fig. 2(h). Moreover, some elongated voids were also found in Fig. 2(g).
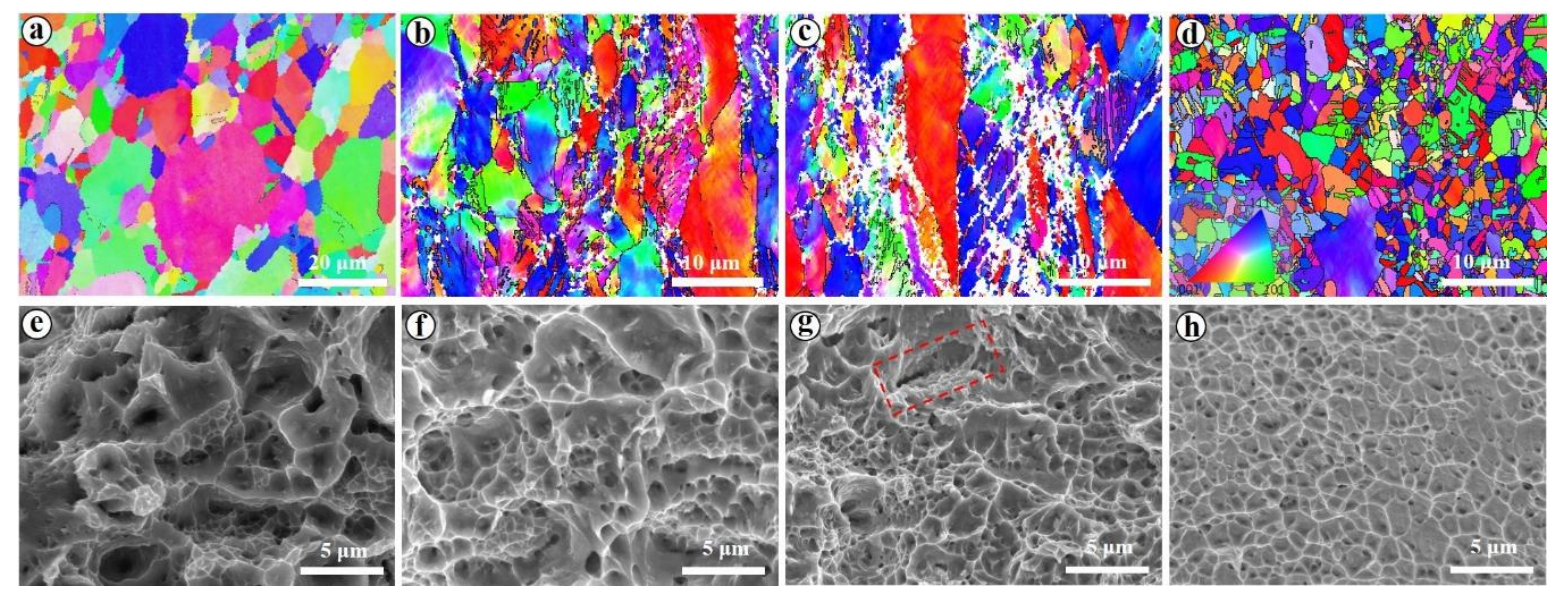

Fig. 2. EBSD mapping of microstructures of the CoCrNi alloys under different treatments: (a) as-SPSed; (b) as-rolled at $25{ }^{\circ} \mathrm{C}$; (c) $50 \%$ rolled at $25{ }^{\circ} \mathrm{C}+$ annealed at $600{ }^{\circ} \mathrm{C}$ for 1 hour; (d) $50 \%$ rolled at $25{ }^{\circ} \mathrm{C}+$ annealed at $700{ }^{\circ} \mathrm{C}$ for $1 \mathrm{~h}$. SEM images showing the fracture morphologies of the CoCrNi alloys processed by (e) SPS, (f) 50\% rolling, (g) $50 \%$ rolling + annealing at $600{ }^{\circ} \mathrm{C}$ for $1 \mathrm{~h}$, and (h) $50 \%$ rolling + annealing at $700{ }^{\circ} \mathrm{C}$ for $1 \mathrm{~h}$.

It is clear in Fig. 1(a) that the cold rolling significantly increased the strength of as-SPSed CoCrNi alloy. In order to understand the dominant strengthening mechanism, detailed microstructural analysis was carried out using TEM. The TEM micrographs in Fig. 3(a) identified the representative microstructure and corresponding selected area diffraction (SAED) pattern L1 of as-rolled CoCrNi alloy with (111) rolling texture. Bright-field TEM image in Fig. 3(b) shows high density of stacking faults (SFs) inside the f.c.c CoCrNi alloy matrix. Partial dislocations were readily to form in such case. In line with the SAED pattern L2, a high density of nanoscale SFs on the (111) and (11) $)$ planes were evidenced in Fig. 3(c). Meanwhile, some SFs intersect with each other, leading to the formation of Lomer-Cottell (LC) locks. The LC locks were highlighted by the white dashed circle in Fig. 3(c). LC locks have been recognized to play a critical role in the strengthening and strain hardening of f.c.c metals [2, 26-29]. The contribution of LCs, responsible 
for strengthening and strain hardening, initiates from their capability to accumulate dislocations [26]. Four dislocation segments are pinned by each LC lock, and the length of LC locks is usually short, similar to a pinning point. According to the line tension model [29], small interspacing between adjacent LC locks would enhance strengthening or hardening.
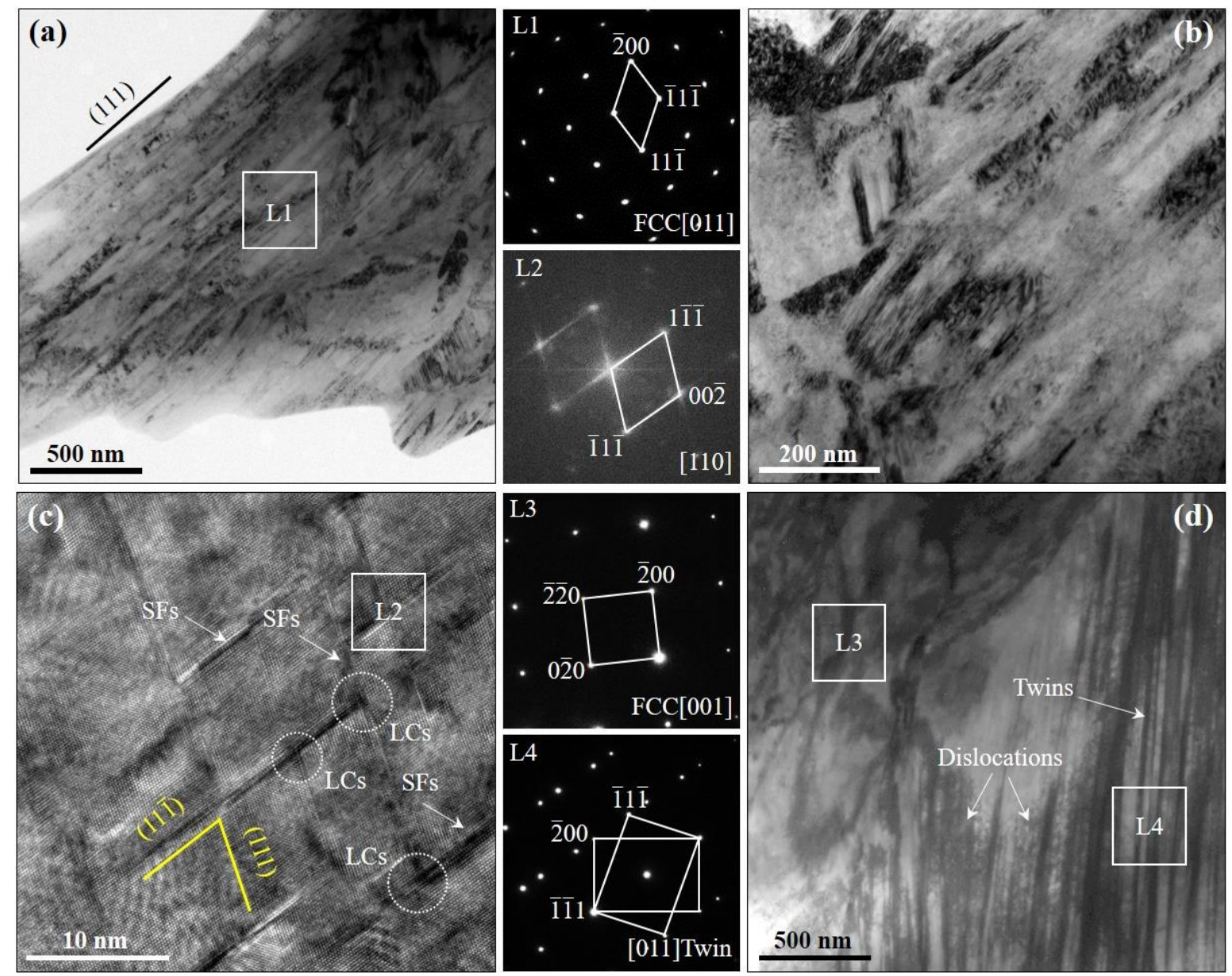

Fig. 3. TEM analysis of the as-rolled CoCrNi medium-entropy alloys: (a) the elongated grains and the SAED pattern L1, showing the f.c.c alloy matrix with a (111) rolling texture; (b) the bright-field TEM image collected from specific areas with stacking faults (SFs); (c) the high-resolution TEM image with SAED pattern L2, showing SFs and Lomer-Cottell locks (LCs); and (d) the bright-field TEM image showing the deformation twinning, the dislocation pile-ups, and the alloy matrix. SAED patterns L3 and L4 correspond to matrix and nanotwins, respectively.

The indexed SAED pattern L4 identified the formation of twins. These twins showed a thickness of a few tens of nanometer, which formed during tensile straining (Fig. 3(d)). Meanwhile, a high density dislocations pile-ups were also observed in the areas near to nanotwins. When the dislocation pile-ups move towards nanotwins, strong blockage of dislocations will impinge on the nanotwin boundaries, causing mechanical strengthening. Strong interaction between the mobile dislocations and the 3D nanotwins network has also been reported by Zhang et al. [20]. The nanotwins enable to act as barriers for mobile dislocations. Dislocations are confined in the nanoscale regions isolated by nanotwins. Four possible dislocation-twin interaction processes have been proposed in the f.c.c polycrystalline $\mathrm{Cu}$ by $\mathrm{Lu}$ et al. [30]. Immobile dislocations (or the highly restricted mobile dislocation in the nanoscale regions) contribute to strengthening while being 
blockaded. Overall, deformation in the as-rolled CoCrNi alloys led to the formation of SFs, LCs, dislocation blockage and nanotwins in microstructure. Such microstructural features are effective by their own and/or interaction to improve the mechanical properties of the as-rolled alloy.

Annealing treatment possesses tuneable ability on both strength and ductility (Fig. 1). The annealing-induced strengthening are closely associated with the microstructural evolution. Usually, annealing treatment facilitates dislocation relaxation [13, 31-33]. When applying annealing at a low temperature of $600{ }^{\circ} \mathrm{C}$, the energy introduced into the materials is relatively low and the recrystallization is not fully completed. The low temperature annealing results in the mixture of recrystallized microstructures and the as-rolled microstructures, as shown in Fig. 2(c). Meanwhile, the dislocations were only partially relaxed. Thus, abundant dislocation cells retained inside grains after annealing at $600{ }^{\circ} \mathrm{C}$, as shown in Fig. 4(a). Many dislocations within the grains have high propensity to migrate to develop the dislocation pile-ups (Supplementary Fig. S4(a). Moreover, dislocation accumulation was observed very close to the crystallite boundaries (Supplementary Fig. S4(b)). The high-density dislocations accumulate at the grain boundaries and, then, entangle with each other. Such dislocation dynamic behaviour suppresses grain slip, leading to increasing strength but with sacrifice of plasticity. In addition, numerous stacking faults (SFs) were also observed in the CoCrNi alloy matrix (Fig. 4(b)). These SFs moved and intersected while nucleating and growing from matrix, resulting in formation of LC locks as shown in Fig. 4(c). 

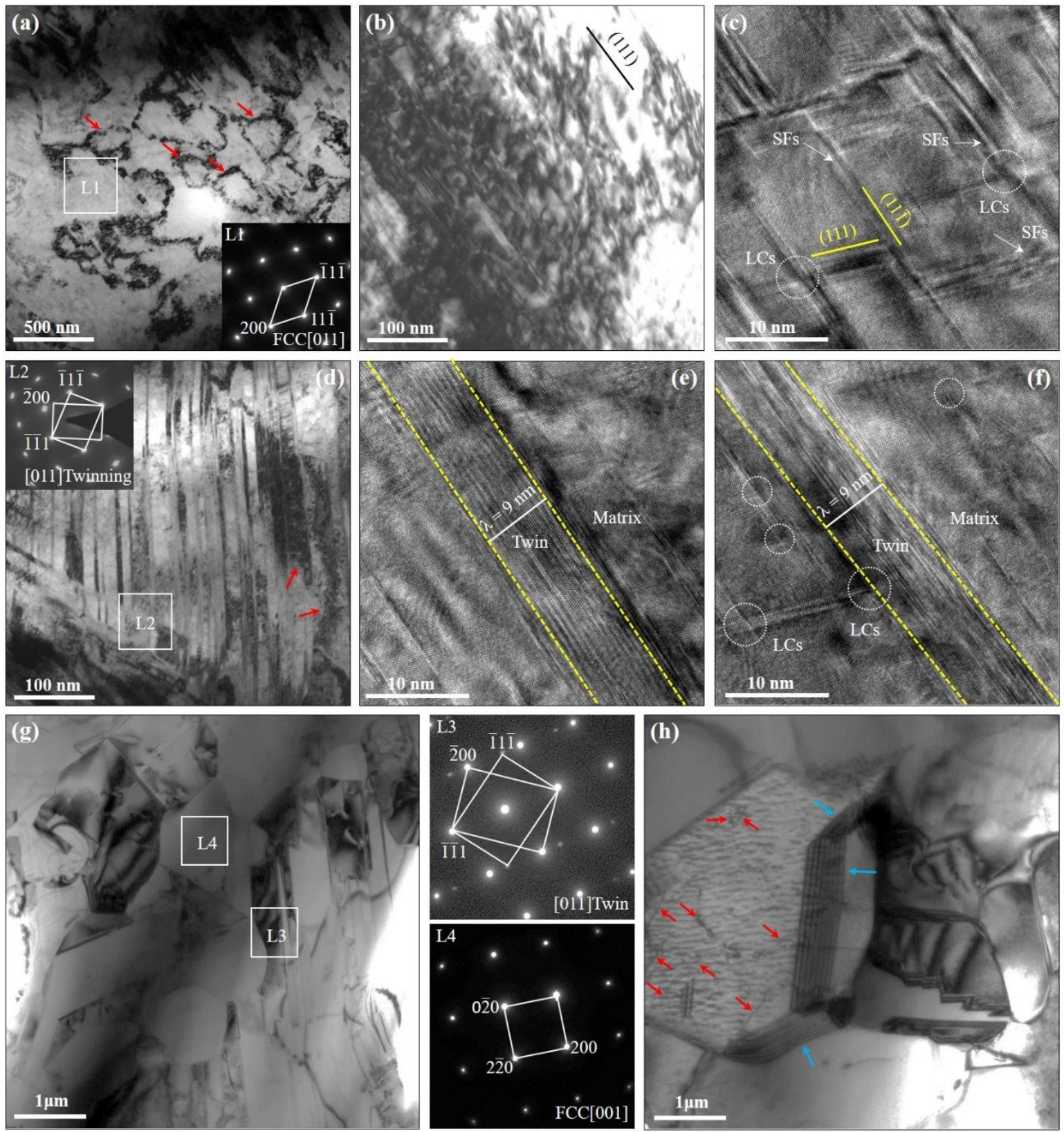

Fig. 4. (a) - (f) Detailed microstructural analysis of the CoCrNi medium-entropy alloys treated by rolling at $25^{\circ} \mathrm{C}$ and annealing at $600{ }^{\circ} \mathrm{C}$ for $1 \mathrm{~h}$. (a) Bright-field TEM micrograph, SAED pattern L1 implies a f.c.c crystal structure, and the red arrows represent the well-defined dislocation cells close to the crystallites. (b) Bright-field TEM micrograph showing the high-density stacking faults (SFs) and nanotwins; (c) high-resolution TEM image indicating the SFs and LCs formation; (d) the high-density deformation nanotwins, with SAED pattern L2 for twinning verification; and (e) and (f) the interaction between nanotwins and LC locks. (g) and (h) TEM images of the CoCrNi medium-entropy alloys treated by rolling at $25{ }^{\circ} \mathrm{C}$ and annealing at $700{ }^{\circ} \mathrm{C}$ for $1 \mathrm{~h}$. (g) The recrystallization-induced grain refinement, with large deformation twins in certain grains. SAED patterns L3 and L4 verify the deformation twins and the f.c.c grain matrix, respectively. (h) The low-density dislocations and stacking faults (SFs) locating inside a grain. The red and blue arrows in (h) show the mobile dislocations and the large 3D SF network, respectively.

Meanwhile, a large number of SFs may transform to develop twins under annealing treatment, 
here, namely annealing twins. The high-density nanotwins were detected inside the matrix grains with corresponding SAED pattern L2, as shown in Fig. 4(d). ab initio modelling has unravelled that $\mathrm{CoCrNi}$ exhibits very high trend for twinning due to its negative stacking-fault energy [20]. Some annealing nanotwins have not experienced sufficient growth when annealing at $600{ }^{\circ} \mathrm{C}$ for $1 \mathrm{~h}$. Thickness of such nanotwins spans from a few to tens of nm (Fig. 4(e)). The interaction between nanotwins and LC locks was also detected in Fig. 4(f). Numerous nanotwins and their intersection provide enough interfaces to block the dislocation motion and jogs [34, 35], thus, strengthening and toughening the CoCrNi alloy. When further increasing the annealing temperatures to $700{ }^{\circ} \mathrm{C}$, the recrystallization was thoroughly completed. Fig. 2(d) shows some grain-refined microstructure due to fully recrystallization. At a higher temperature of $700{ }^{\circ} \mathrm{C}$, twins accomplished full growth to become larger, as shown in Fig. 4(g). SAED patterns L3 and L4 confirm the twins and matrix, respectively. However, compared with the microstructures at $600{ }^{\circ} \mathrm{C}$ in Fig. 4, there is only a much lower density of dislocations observed at $700{ }^{\circ} \mathrm{C}$ annealing in Fig. 4(h). Comparing Fig. 3(c) with Fig. 4(c), the density of SFs and LC locks after annealing at $600{ }^{\circ} \mathrm{C}$ is much higher than its as-rolled counterpart. Comparing Fig. 3(d) with Fig. 4(a), the dislocation pile-ups and dislocation cells occurred in the as-rolled and the annealed samples $\left(600{ }^{\circ} \mathrm{C}\right)$, respectively. The mechanical improvement of CoCrNi alloys merely depends on tunnelling lattice defects.

In summary, the mechanical properties of $\mathrm{CoCrNi}$ medium-entropy alloys varied with tunnelling lattice defects. Specifically, the as-SPSed CoCrNi alloy exhibited the optimal plastic flow with $47.5 \%$ fracture strain, but smallest YS (0.48 GPa), UTS (0.86 GPa) and hardness (215.2 Hv) values. Such excellent plasticity mainly results from a heterogeneous grain structures. The CoCrNi alloy, rolled at $25{ }^{\circ} \mathrm{C}$ and annealed at $600{ }^{\circ} \mathrm{C}$ for $1 \mathrm{~h}$, presented the highest YS (1.43 GPa), UTS $(1.61 \mathrm{GPa})$ and hardness $(407.6 \mathrm{Hv})$ values among all samples, but the lowest fracture strain $\sim 2.3 \%$. Strengthening in this case initiates from the appropriate heterostructures, the abundant residual dislocation cells, the high-density small stacking faults (SFs), the ultrafine nanotwins $(\sim 9 \mathrm{~nm})$, and the Lomer-Cottell (LC) locks. A good combination of YS/UTS $(0.70 / 1.02 \mathrm{GPa})$ and fracture strain $(27.6 \%)$ occurred in the samples rolled at $25{ }^{\circ} \mathrm{C}$ and annealed at $700{ }^{\circ} \mathrm{C}$ for $1 \mathrm{~h}$. This moderate strength-ductility synergy happens due to the grain refinement, the large deformation twinning, the low density dislocations, and the large 3D SF networks. For the CoCrNi alloys purely rolled at 25 ${ }^{\circ} \mathrm{C}$, the YS, UTS and hardness reached $1.24 \mathrm{GPa}, 1.41 \mathrm{GPa}$ and $350.7 \mathrm{Hv}$ respectively, which corresponds to the microstructure feature, i.e. the (111) texture, the large deformation twins, the low-density stacking faults, and the low density LC locks.

\section{Declaration of Competing Interest}

The authors declare that they have no known competing financial interests or personal relationships that could have appeared to influence the work reported in this paper.

\section{Acknowledgement}

This project was financially supported by National Natural Science Foundation of China with grant No. 51404302. Zhilin Liu thanks Innovation Driven Program of Central South University (Grant No. 2019CX006). 


\section{References}

[1] M. Yang, D. Yan, F. Yuan, P. Jiang, E. Ma, X. Wu, Proc. Natl. Acad. Sci. 115 (2018) 7224-7229.

[2] Y. Ma, F. Yuan, M. Yang, P. Jiang, E. Ma, X. Wu, Acta Mater. 148 (2018) 407-418.

[3] XH. Du W.P. Li, H.T. Chang, T. Yan, G.S. Duan, B.L. Wu, J.C. Huang, F.R. Chen, C.T. Liu, W.

S. Chuang, Y. Lu, M.L. Sui, E. W. Huang, Nat. Commun. 11 (2020) 2390.

[4] J.P. Liu, J.X. Chen, T.W. Liu, C. Li, Y. Chen, L.H. Dai, Scripta Mater. 181 (2020) 19-24.

[5] R. Wen, C. You, L. Zeng, H. Wan, X. Zhang, J. Mater. Sci. (2020) doi: 10.1007/s10853-020-04870-6.

[6] S. Praveen, J.W. Bae, P. Asghari-Rad, J.M. Park, H.S. Kim, Mater. Sci. Eng. A 734 (2018) 338340 .

[7] G. Dan Sathiaraj, W. Skrotzki, A. Pukenas, R. Schaarschuch, R. Jose Immanuel, S.K. Panigrahi, J. Arout Chelvane, S.S. Satheesh Kumar, Intermetallics 101 (2018) 87-98.

[8] G.W. Hua, L.C. Zeng, H. Du, X.W. Liu, Y. Wu, P. Gong, Z.T. Fan, Q. Hu, E.P. George, J. Mater. Sci. Technol. 54 (2020) 196-205.

[9] B. Gludovatz, A. Hohenwarter, K.V.S. Thurston, H. Bei, Z. Wu, E.P. George, R.O. Ritchie, Nat Commun. 7 (2016) 10602.

[10] Y.L. Zhao, T. Yang, Y. Tong, J. Wang, J.H. Luan, Z.B. Jiao, D. Chen, Y. Yang, A. Hu, C.T. Liu, J.J. Kai, Acta Mater. 138 (2017) 72-82.

[11] I. Moravcik, J, Cizek, Z. Kovacova, J. Nejezchlebova, M. Kitzmantel, Mater. Sci. Eng. A 701 (2017) 370-380.

[12] X. Feng, H. Yang, R. Fan, W. Zhang, F. Meng, B. Gan, Y. Lu, Mater. Sci. Eng. A 788 (2020) 139591.

[13] M. Schneidera, E.P. George, T.J. Manescau, T. Záležák, J. Hunfeld, A. Dlouhý, G. Eggeler, G. Laplanche, Int. J. Plast. 124 (2020) 155-169.

[14] J.Y. Wang, H.L. Yang, H. Huang, J.M. Ruan, S.X. Ji, J. Alloys. Compd. 798 (2019) 576-586.

[15] X.W. Liu, G. Laplanche, A. Kostka, S.G. Fries, J. Pfetzing-Micklich, G. Liu, E.P. George, J. Alloys Compd. 775 (2019) 1068e1076

[16] R. Zhang, S. Zhao, J. Ding, Y. Chong, T. Jia, C. Ophus, M. Asta, R.O. Ritchie, A.M. Minor, Nature 581 (2020) 283-287.

[17] Y.Y. Shang, Y. Wu, J.Y. He, X.Y. Zhu, S.F. Liu, H.L. Huang, K. An, Y. Chen, S.H. Jiang, H. Wang, X.J. Liu, Z.P. Lu, Intermetallics 106 (2019) 77-87.

[18] Z. Li, S. Zhao, R.O. Ritchie, M.A. Meyers, Prog. Mater. Sci. 102 (2019) 296-345.

[19] E.P. George, D. Raabe, R.O. Ritchie, Nat. Rev. Mater. 4 (2019) 515-534.

[20] Z. Zhang, H. Sheng, Z. Wang, B. Gludovatz, Z. Zhang, E.P. George, Q. Yu, S.X. Mao, R.O. Nat. Commun. 8 (2017) 14390.

[21] C.E. Slone, J. Miao, E.P. George, M.J. Mills, Acta Mater. 165 (2019) 496-507.

[22] J.Y. He, H. Wang, H.L. Huang, X.D. Xu, M.W. Chen, Acta Mater. 102 (2016) 187-196.

[23] H.L. Huang, Y. Wu, J.Y. He, H. Wang, X.J. Liu, Adv. Mater. 29 (2017) 1701678.

[24] Z.W. Wang, I. Baker, W. Guo, J.D. Poplawsky, Acta Mater. 126 (2017) 346-360.

[25] I. Baker, F.L. Meng, M. Wu, A. Brandenberg, J. Alloy Compd. 656 (2016) 458-464.

[26] W. Wu, S. Ni, Y. Liu, B. Liu, M. Song, Mater. Charact. 127 (2017) 111-115.

[27] X.L. Wu, Y.T. Zhu, Y.G. Wei, Q. Wei, Phys. Rev. Lett. 103 (2009) 205504.

[28] V. Yamakov, D. Wolf, S.R. Phillpot, A.K. Mukherjee, H. Gleiter, Nat. Mater. 1 (2002) 45-48.

[29] L. Dupuy, M.C. Fivel, Acta Mater. 50 (2002) 4873-4885. 
[30] L. Lu, Z.S. You, K. Lu, Scr. Mater. 66 (2012) 837-842.

[31] P.P. Bhattacharjee, G.D. Sathiaraj, M. Zaid, J.R. Gatti, C. Lee, J. Alloys. Compd. 587 (2014) $544-552$.

[32] C. Haase, L.A. Barrales-Mora, Acta Mater. 150 (2018) 88-103.

[33] J. Gu, M. Song, Scripta Mater. 162 (2019) 345-349.

[34] Y.L. Zhang, J.G. Li, X.G. Wang, Y.P. Lu, Y.Z. Zhou, X.F. Sun, J. Mater. Sci. Technol. 35 (2019) 902-906.

[35] J.H. Lee, T.B. Holland, A.K. Mukherjee, X.H. Zhang, H.Y. Wang, Sci. Rep. 3 (2013) 1061.

\section{Supplementary Materials}
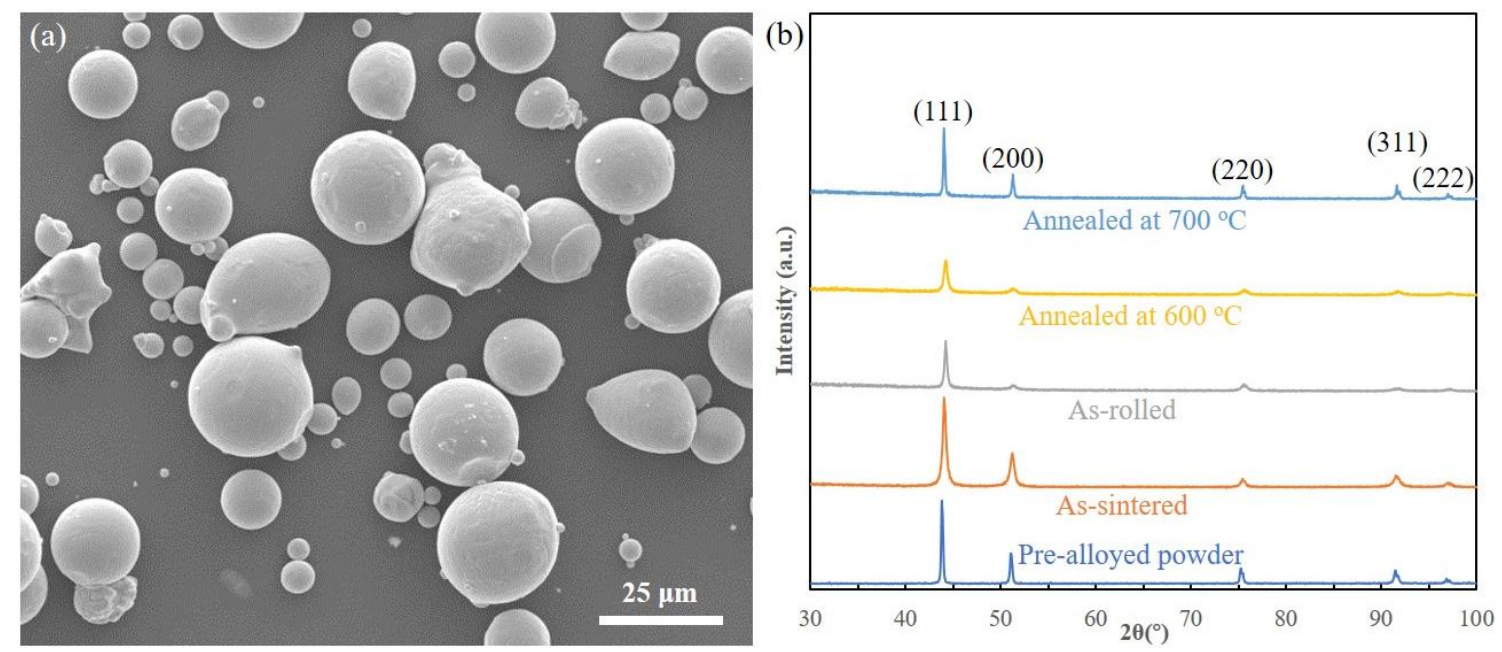

Fig. S1. (a) SEM image showing the typical morphology of raw CoCrNi alloy powders, prepared by $\mathrm{N}_{2}$ gas atomization; (b) XRD spectra of the raw powders and the CoCrNi alloys for different treatments. 


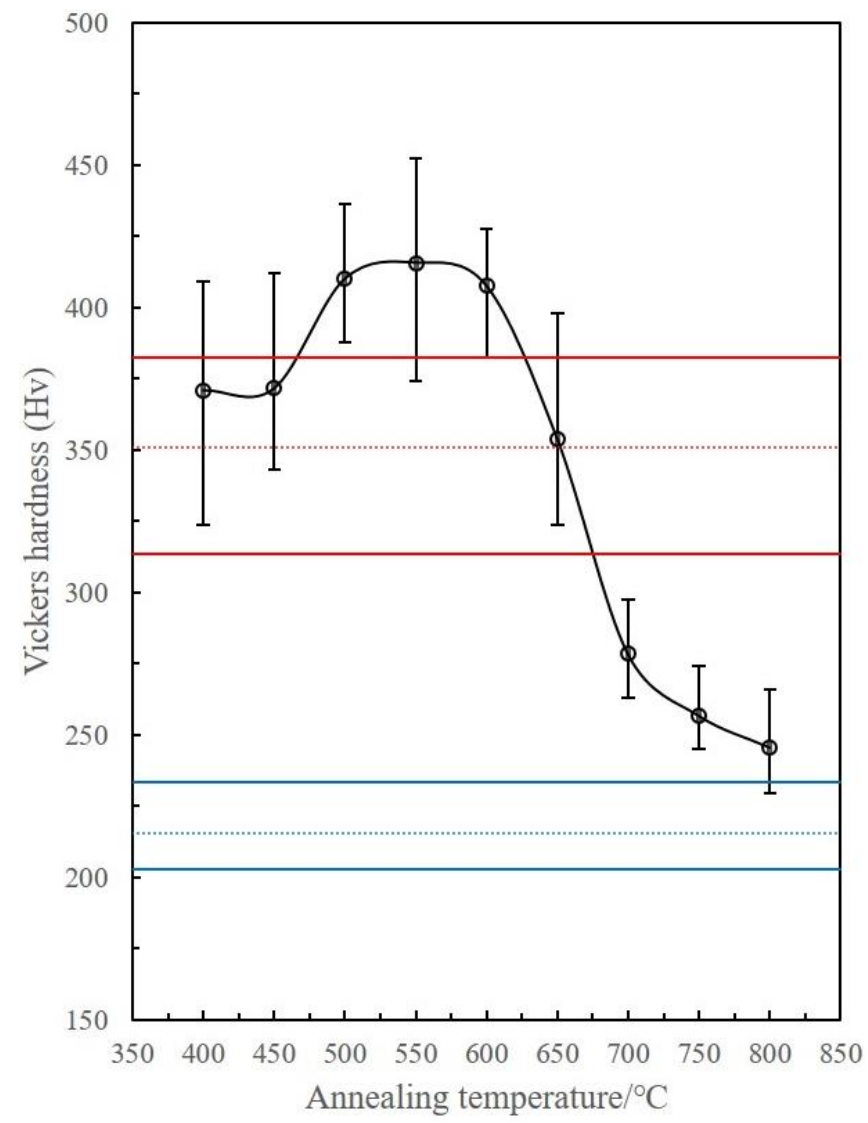

Fig. S2. Vickers hardness of the $\mathrm{CrCoNi}$ alloy under different treatments. All the annealing was retained for $1 \mathrm{~h}$ regardless of various temperature.

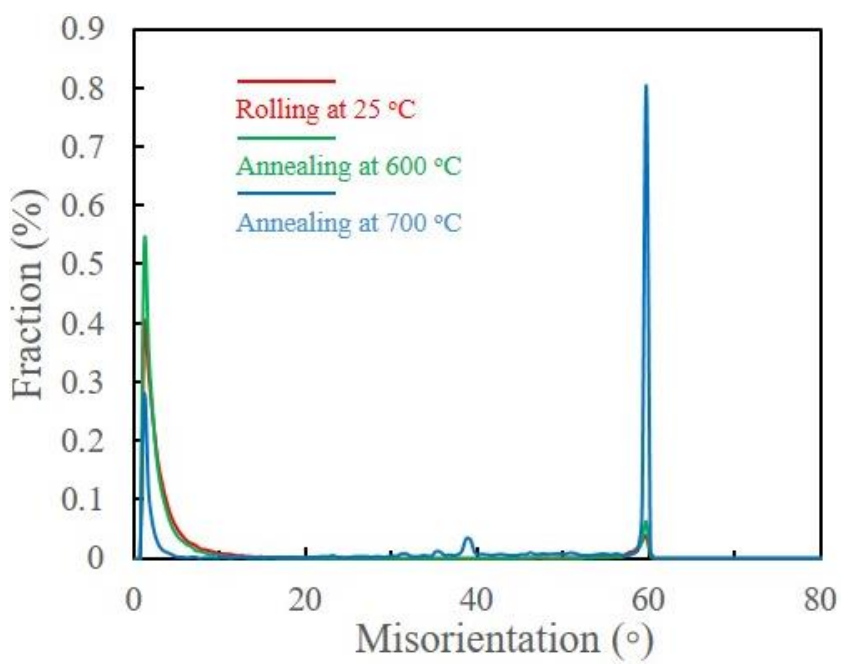

Fig. S3. The misorientation angle distributions of grain structures in the $\mathrm{CoCrNi}$ alloys processed by rolling at $25{ }^{\circ} \mathrm{C}$, rolling at $25{ }^{\circ} \mathrm{C}+$ annealing at $600{ }^{\circ} \mathrm{C}$ for 1 hour, and rolling at $25{ }^{\circ} \mathrm{C}+$ annealing at $700{ }^{\circ} \mathrm{C}$ for $1 \mathrm{~h}$, respectively. 

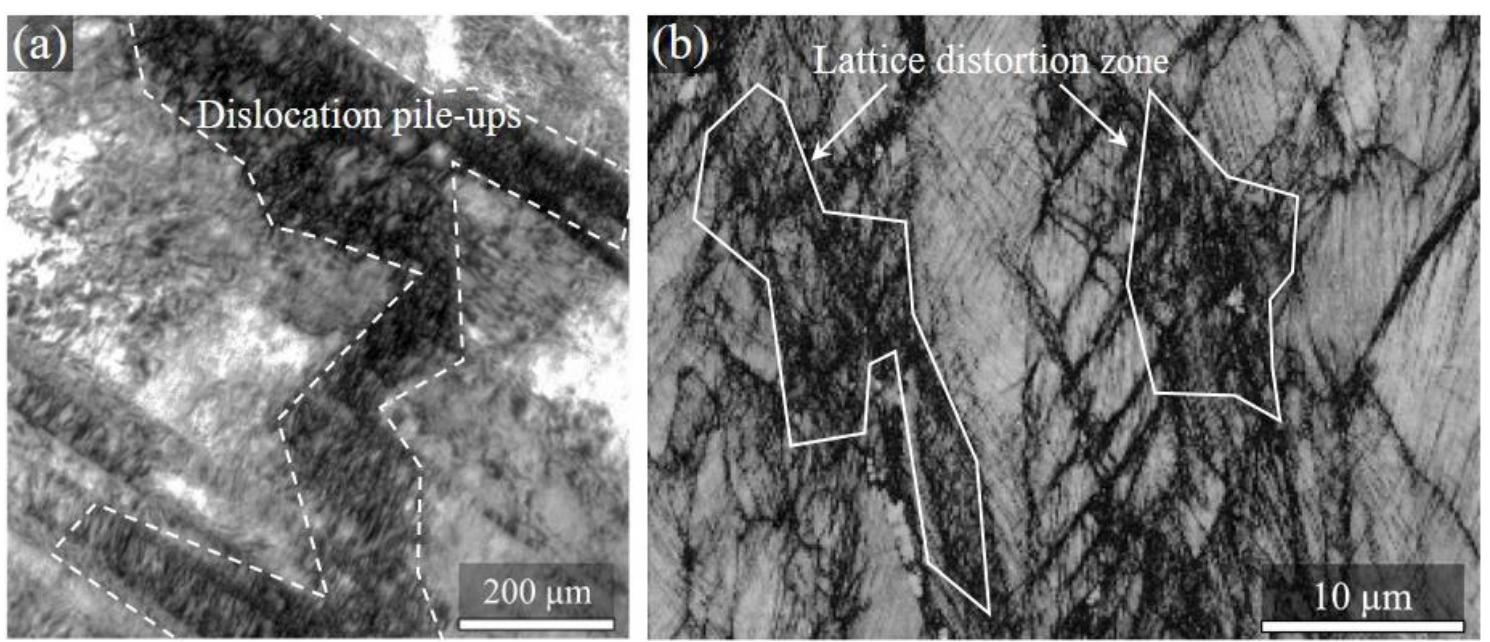

Fig. S4. (a) Bright-field TEM image, showing abundant dislocation pile-ups. (b) EBSD band contrast, displaying the dislocation accumulation near to the crystallite boundaries in the $\mathrm{CoCrNi}$ alloys after rolling at $25^{\circ} \mathrm{C}$ and annealing at $600{ }^{\circ} \mathrm{C}$. 